\title{
Food Insecurity, Nutritional Status, and Factors Associated with Malnutrition among People Living with HIV/AIDS Attending Antiretroviral Therapy at Public Health Facilities in West Shewa Zone, Central Ethiopia
}

\author{
Delelegn Yilma Gebremichael (D), ${ }^{1}$ Kokeb Tesfamariam Hadush, ${ }^{1}$ \\ Ermiyas Mulu Kebede, ${ }^{1}$ and Robel Tezera Zegeye ${ }^{2}$ \\ ${ }^{1}$ College of Medicine and Health Sciences, Department of Public Health, Ambo University, P.O. Box 19, Ambo, Ethiopia \\ ${ }^{2}$ College of Medicine and Health Sciences, School of Medicine, Addis Ababa University, Addis Ababa, Ethiopia
}

Correspondence should be addressed to Delelegn Yilma Gebremichael; delelegnyilma@gmail.com

Received 23 September 2017; Revised 3 March 2018; Accepted 27 March 2018; Published 6 May 2018

Academic Editor: Himanshu Garg

Copyright (C) 2018 Delelegn Yilma Gebremichael et al. This is an open access article distributed under the Creative Commons Attribution License, which permits unrestricted use, distribution, and reproduction in any medium, provided the original work is properly cited.

\begin{abstract}
Background. In resource limited settings, HIV/AIDS patients lack access to sufficient nutritious foods, which poses challenges to the success of antiretroviral therapy. HIV/AIDS and malnutrition are still major public health problems in Ethiopia. Though measuring nutritional status is an essential part of ART program, little evidence exists on food insecurity and nutritional status of HIV/AIDS patients in Ethiopia. Hence, the study aimed to determine food insecurity and nutritional status and contextual determinants of malnutrition among HIV/AIDS patients in West Shewa Zone, Ethiopia. Methods. Institution-based cross-sectional study was conducted among HIV/ADIS patients who have been attending antiretroviral therapy at public health facilities in West Shewa Zone from April to May 2016, Ethiopia. The sample size was 512 and study participants were selected from each facilities using systematic random sampling method. Data were collected using pretested questionnaire by trained data collectors. Data were entered to Epi-Info 3.5.1 for Windows and analyzed using SPSS version 22. Logistic regression analyses were conducted to determine independent factors associated with malnutrition. Results. Prevalence of malnutrition was 23.6\% (95\% CI: 19.7\%-27.4\%) and prevalence of household food insecurity was 35.2\% (95\% CI: 31.1\%-39.0\%). Factors significantly associated with malnutrition among HIV/AIDS patients were unemployment (AOR $=3.4$; 95\% CI: 1.8-5.3), WHO clinical stages III/IV (AOR = 3.3; 95\% CI: 1.8-6.5), CD4 count less than 350 cells $/ \mu \mathrm{l}(\mathrm{AOR}=2.0 ; 95 \% \mathrm{CI}: 1.8-4.2)$, tuberculosis $(\mathrm{AOR}=2.3 ; 95 \%$ CI: $1.3-4.9)$, duration on antiretroviral therapy $(\mathrm{AOR}=1.8 ; 95 \% \mathrm{CI}: 1.2-2.9)$, and household food insecurity (AOR $=5.3 ; 95 \% \mathrm{CI}$ : 2.5-8.3). Conclusions. The findings revealed high prevalence of malnutrition and household food insecurity among HIV/AIDS patients attended ART. The negative interactive effects of undernutrition, inadequate food consumption, and HIV infection demand effective cross-sectorial integrated programs and effective management of opportunistic infections like tuberculosis.
\end{abstract}

\section{Background}

The burden of HIV/AIDS remains unacceptably high in low and middle income, particularly in Africa [1]. In resource limited settings, many PLWHA lack access to sufficient quantities of nutritious foods, which poses additional challenges to the success of antiretroviral therapy (ART) $[2,3]$. The combined impacts of food insecurity and HIV/AIDS place further strain on already limited household resources as affected family members struggle to meet household food needs [4]. Malnutrition and food insecurity are associated with increased mortality and poor clinical outcomes among people living with HIV/AIDS [5]. The nutritional problems have been shown to be significant and contribute to morbidity and mortality in HIV+/AIDS patients [6]. Evidence indicates that even relatively small losses in weight (5\%) are associated with decreased survival rate [7]. There is an urgent need for renewed focus on and use of resources for nutrition as 
a fundamental part of the comprehensive package of care at country level $[8,9]$.

People living with HIV (PLWHA) are more likely to become malnourished due to reduced food intake, poor absorption of nutrients, and changes in the way the body uses nutrients it receives or has stored [10]. In Ethiopia, undernutrition prevalence was reported from $12.3 \%$ [11] to $46.8 \%$ [12] among PLWHA and high prevalence of food insecurity among PLWHA was reported from $40.4 \%$ [13] to $87.4 \%$ [14]. Food insecurity and undernutrition are still significant problems among PLWHA on ART in Ethiopia despite advances in their treatment and survival [12-17]. However, little is known about contextual factors associated with the complex interactions of food insecurity and malnutrition among PLWHA in Ethiopia. Hence, this study intended to assess contextual factors of undernutrition among PLWHA because understanding the relationships between HIV, undernutrition, and food insecurity has important implications for the effective integration of nutritional interventions into HIV programs.

\section{Materials and Methods}

The study was conducted in West Shewa Zone which is one of the Zones in Oromia region located 114 kilometers west of capital city of Ethiopia. According to 2015 West Shewa Zone report, 18,642 patients were ever enrolled, 10,988 were ever started ART, and 8006 were on ART in West Shewa Zone. There are 3 hospitals and 83 health centers that currently provide protective, promotive, preventive, curative, and rehabilitative services. Among 83 facilities, 24 of them provide antiretroviral treatment (ART) services in West Shewa Zone. The study used institution-based cross-sectional study design. The source population was people living with HIV attending antiretroviral therapy at public health facilities in West Shewa Zone and the study population was HIV/ADIS patients aged 18 years or older who have been attending ART at public health facilities in West Shewa Zone from April to May 2016, Ethiopia.

Sample size for this study was determined using the formula for the estimation of single proportion. $p=$ proportion of HIV positive individuals with malnutrition taken as $28 \%$ [15], $d=$ margin of error $=0.05$, and $Z=$ value of standard normal distribution ( $Z$ statistic) at $95 \%$ confidence level $(z=1.96)$. After being multiplied by 1.5 design effect and adding $10 \%$ nonresponse rate, the final sample was 512 . Among 24 health facilities which provide ART services in West Shewa Zone, six health facilities were randomly selected using lottery method and the samples were proportionally allocated to each of the selected health facilities. Then the study participants were selected from each of the health facilities using systematic random sampling method.

Clinical, laboratory, and ART data were collected by trained health professionals through reviewing records from ART entry registration book and individual follow-up form using prepared pretested data collection form. Household food insecurity was assessed using Household Food Insecurity Access Scale (HFIAS) [18]. It consists of nine questions on experiences of food insecurity, with possible responses of never, rarely, sometimes, or often. The highest score for HFIAS is 27; the higher the score, the greater the food insecurity. Food insecurity is considered when the individual (PLHIV) answer $>2$ to affirmative questions of food insecurity scale resulting from financial resource constraint. The height and weight of the patients were measured in light clothing and bare foots calibrated to $0.5 \mathrm{~cm}$ and $0.5 \mathrm{~kg}$, respectively. Height was measured while the patients were standing erect in a Frankfurt position and the weight was measured on a standing scale. BMI (Weight $(\mathrm{kg}) /$ Height2 (m)) was calculated to assess nutritional status. The standard cutoffs were used to define nutritional status. If individual's BMI was less than $18.5 \mathrm{~kg} / \mathrm{m} 2$, the individual was considered undernourished/malnourished; when it was greater than or equal to $25.0 \mathrm{~kg} / \mathrm{m} 2$, the individual was considered overweight; and if it was $18.5-24.9 \mathrm{~kg} / \mathrm{m} 2$, the individual was considered normal.

Data were checked for completeness and consistency, coded, and entered to Epi-Info 3.5.1 for Windows and analyzed using SPSS version 22 for Windows. Study participants' characteristics were described in terms of mean (standard deviation) and median (interquartile range) for continuous data and frequency distribution for categorical data. Chi square $\left(\chi^{2}\right)$ test was used for categorical variables. Multicollinearity between explanatory variables was checked using variance inflation factors (VIF). Logistic regression analysis was carried out to identify the correlates of nutritional status. All explanatory variables that were significantly associated with the outcome variable in the bivariate analyses $(P<0.05)$ were entered in to multivariate logistic regression model. Crude and adjusted odds ratios with their $95 \%$ confidence interval (CI) were determined and statistical significant association was asserted based on $P$ value less than 0.05 .

Ethical clearance was obtained from the Institutional Review Board (IRB) of Ambo University. Following the approval by IRB, official letter of cooperation was written to the concerned bodies from the College of Medicine and Health Sciences research office, about the purpose of the study to facilitate the support and commitment of responsible bodies. Written consent from each of the study subjects was taken. Study participants' confidentiality was maintained. No personal identifiers were used on data collection forms and the recorded data were not accessed by a third person, except the Principal Investigators.

\section{Results}

3.1. Sociodemographic Characteristics of People Living with HIV/AIDS. A total of 505 study participants responded to the study with response rate of $98.6 \%$. The mean age (SD) was $34.41( \pm 7.47)$ years and $368(72.9 \%)$ of the study participants were in 25 to 44 years' age group. More than half of the study participants, $264(52.3 \%)$ were females. Majority of the study participants, 350 (69.3\%) were rural resident and 337 (66.7\%) were married. Out of the total respondents, 417 (82.6\%) were Oromo in ethnicity and 299(59.2\%) were Orthodox Christians. Regarding education, 324 (64.2\%) respondents were literate and $423(83.8 \%)$ of participants were employed (Table 1). 
TABLE 1: Sociodemographic characteristics of HIV/AIDS patients attending antiretroviral therapy in public health facilities, West Shewa Zone, Ethiopia, 2017.

\begin{tabular}{|c|c|c|}
\hline Sociodemographic characteristics & Frequency & Percent (\%) \\
\hline \multicolumn{3}{|l|}{ Age } \\
\hline $18-24$ & 38 & 7.5 \\
\hline $25-34$ & 175 & 34.7 \\
\hline $35-44$ & 193 & 38.2 \\
\hline $45-54$ & 82 & 16.2 \\
\hline$>54$ & 17 & 3.4 \\
\hline \multicolumn{3}{|l|}{ Sex } \\
\hline Male & 241 & 47.7 \\
\hline Female & 264 & 52.3 \\
\hline \multicolumn{3}{|l|}{ Residence } \\
\hline Rural & 350 & 69.3 \\
\hline Urban & 155 & 30.7 \\
\hline \multicolumn{3}{|l|}{ Marital status } \\
\hline Single & 92 & 18.2 \\
\hline Married & 337 & 66.7 \\
\hline Widowed & 51 & 10.1 \\
\hline Divorced/separated & 25 & 5.0 \\
\hline \multicolumn{3}{|l|}{ Ethnicity } \\
\hline Oromo & 417 & 82.6 \\
\hline Amhara & 71 & 14.0 \\
\hline Others & 17 & 3.4 \\
\hline \multicolumn{3}{|l|}{ Religion } \\
\hline Protestant & 177 & 35.1 \\
\hline Orthodox & 299 & 59.2 \\
\hline Muslim & 24 & 4.7 \\
\hline Others & 5 & 1.0 \\
\hline \multicolumn{3}{|l|}{ Education } \\
\hline Illiterate & 181 & 35.8 \\
\hline Literate & 324 & 64.2 \\
\hline \multicolumn{3}{|l|}{ Occupation } \\
\hline Employed & 423 & 83.8 \\
\hline Unemployed & 82 & 16.2 \\
\hline
\end{tabular}

3.2. Clinical Characteristics and Household Food Security Status of People Living with HIV/AIDS. The patients median (IQR) duration of ART treatment was 44 (22-68) months. Nearly half $(47.7 \%)$ of the study participants were at clinical WHO stage III and a quarter $(25.4 \%)$ were at clinical WHO stage IV. Baseline median CD4 count (IQR) was 135 (68-211) cells/ $\mu$ l. The most recent median CD4 count (IQR) was 232 (134-328) cells/ $\mu$ l. More than three-quarters (76.8\%) of the study participants had CD 4 count less than 350 cells $/ \mu l$. The history of TB/HIV coinfection and anemia was $12.5 \%$ and $20.6 \%$, respectively. The prevalence of household food insecurity was $35.2 \%$ (95\% CI: 31.1\%-39.0\%) (Table 2).

3.3. Nutritional Status of People Living with HIV/AIDS. Concerning nutritional status, $23.6 \%$ (95\% CI: 19.7\%-27.4\%) of respondents were undernourished. The result showed that undernutrition was significantly different for men (18.7\%)
TABLE 2: Clinical characteristics of HIV/AIDS patients attending antiretroviral therapy in public health institutions, West Shewa Zone, Ethiopia, 2017.

\begin{tabular}{lcc}
\hline Clinical characteristics & Frequency & Percent (\%) \\
\hline WHO clinical Stage & & \\
$\quad$ Stage I & 49 & 9.7 \\
Stage II & 87 & 17.2 \\
$\quad$ Stage III & 241 & 47.7 \\
$\quad$ Stage IV & 128 & 25.4 \\
Recent CD4 count & & \\
$\quad<350$ cells/ $\mu$ l & 388 & 76.8 \\
$\quad \geq 350$ cells/ $\mu$ l & 117 & 23.2 \\
Duration on ART & & \\
$\quad<44$ months & 261 & 51.7 \\
$\quad \geq 44$ months & 244 & 48.3 \\
Tuberculosis & & \\
$\quad$ Yes & 63 & 12.5 \\
$\quad$ No & 442 & 87.5 \\
Anemia status & & \\
$\quad$ Normal & 401 & 79.4 \\
$\quad$ Anemic & 104 & 20.6 \\
Household food security & & 35.2 \\
$\quad$ Secure & 327 & \\
Insecure & 178 & \\
\hline
\end{tabular}

compared to women $(28 \%)(P$ value $=0.009)$. Malnutrition was higher among widowed (33.3\% respondents compared with married participants $(21.9 \%), P$ value $=0.032)$. There was also significant difference in malnutrition status between literate $(19.8 \%)$ and illiterate respondents $(30.4 \%)(P$ value $=$ $0.004)$. Similarly, unemployed respondents had significantly higher undernutrition (40.2\%) compared with employed counterparts $(20.8 \%)(P$ value $=0.0001)$.

Malnutrition was also significantly different with WHO clinical stages $(37.5 \%, 24.1 \%, 10.3 \%$, and $8.2 \%$ of stage IV, stage III, stage II, and stage I patients, resp., were undernourished, $P$ value $=0.0001)$. PLWHA who had CD4 count less than 350 cells/ $\mu$ l had significantly higher malnutrition (27.6\%) compared with PLWHA who had CD4 count greater than 350 cells $/ \mu$ l $(10.3 \%)(P$ value $=0.003)$. TB/HIV coinfected patients had significantly higher undernutrition (39.7\%) compared to their counterparts (21.3\%), $P$ value $=0.002$. The prevalence of undernourishment was higher in PLWHA who were on ART for less than 44 months (29.9\%) than those who were on ART for more than 44 months $(16.8 \%)$ $(P$ value $=0.004)$. Likewise, household food unsecured PLWHA (48.9\%) were significantly undernourished higher than household food secured counterparts $(9.8 \%)(P=$ 0.0001) (Table 3).

3.4. Factors Associated with Nutritional Status among HIV/AIDS Patients. The independent factors significantly associated with nutritional status among people living with HIV/AIDS were occupation, WHO clinical stage, CD4 count, tuberculosis, duration on ART, and household food 
TABLE 3: Nutritional status of HIV/AIDS patients attending antiretroviral therapy in public health facilities, West Shewa Zone, Ethiopia, 2017.

\begin{tabular}{|c|c|c|c|c|}
\hline \multirow{3}{*}{ Variables } & \multicolumn{2}{|c|}{ Undernourished } & \multirow{3}{*}{$\chi^{2}$-value } & \multirow{3}{*}{$P$ value } \\
\hline & No & Yes & & \\
\hline & Number (\%) & Number (\%) & & \\
\hline \multicolumn{5}{|l|}{ Age } \\
\hline $18-24$ & $31(81.6)$ & $7(18.4)$ & \multirow{5}{*}{0.6} & \multirow{5}{*}{0.968} \\
\hline $25-34$ & $134(76.6)$ & $42(23.4)$ & & \\
\hline $35-44$ & $146(75.7)$ & $47(24.3)$ & & \\
\hline $45-54$ & $62(75.6)$ & $20(24.4)$ & & \\
\hline$>54$ & $13(76.5)$ & $4(23.5)$ & & \\
\hline \multicolumn{5}{|l|}{ Sex } \\
\hline Male & $196(81.3)$ & 45 (18.7) & \multirow{2}{*}{6.8} & \multirow{2}{*}{0.009} \\
\hline Female & $190(72.0)$ & $74(28.0)$ & & \\
\hline \multicolumn{5}{|l|}{ Residence } \\
\hline Rural & $263(75.1)$ & $87(24.9)$ & \multirow{2}{*}{1.1} & \multirow{2}{*}{0.299} \\
\hline Urban & $123(79.3)$ & $32(20.7)$ & & \\
\hline \multicolumn{5}{|l|}{ Marital status } \\
\hline Single & $67(72.8)$ & $25(27.2)$ & \multirow{4}{*}{8.8} & \multirow{4}{*}{0.032} \\
\hline Married & $263(78.1)$ & $74(21.9)$ & & \\
\hline Widowed & $34(66.7)$ & $17(33.3)$ & & \\
\hline Divorced/separated & $21(88.0)$ & $3(12.0)$ & & \\
\hline \multicolumn{5}{|l|}{ Ethnicity } \\
\hline Oromo & $316(75.8)$ & $101(24.2)$ & \multirow{3}{*}{2.5} & \multirow{3}{*}{0.293} \\
\hline Amhara & $55(77.5)$ & $16(22.5)$ & & \\
\hline Others & $15(88.2)$ & $2(11.8)$ & & \\
\hline \multicolumn{5}{|l|}{ Religion } \\
\hline Protestant & $139(78.5)$ & $38(21.5)$ & & \\
\hline Orthodox & $223(74.6)$ & $76(25.4)$ & 1.3 & 0.72 \\
\hline Muslim & $20(83.3)$ & $4(16.7)$ & 1.3 & 0.12 \\
\hline Others & $4(80.0)$ & $1(20.0)$ & & \\
\hline Education & & & & \\
\hline Illiterate & $126(69.6)$ & $55(30.4)$ & 71 & 0.004 \\
\hline Literate & $260(80.2)$ & $64(19.8)$ & & \\
\hline Occupation & & & & \\
\hline Employed & $337(79.2)$ & $86(20.8)$ & 289 & 0.0001 \\
\hline Unemployed & $49(59.8)$ & $33(40.2)$ & 28.9 & 0.0001 \\
\hline WHO clinical Stage & & & & \\
\hline Stage I & $45(91.8)$ & $4(8.2)$ & & \\
\hline Stage II & $78(89.7)$ & $9(10.3)$ & 30.8 & 0.0001 \\
\hline Stage III & $183(75.9)$ & $58(24.1)$ & 30.8 & 0.0001 \\
\hline Stage IV & $80(62.5)$ & $48(37.5)$ & & \\
\hline $\mathrm{CD} 4$ count & & & & \\
\hline$<350$ cells $/ \mu \mathrm{l}$ & $281(72.7)$ & $107(27.6)$ & 8.7 & 0.003 \\
\hline$\geq 350$ cells $/ \mu \mathrm{l}$ & $105(89.7)$ & $12(10.3)$ & 8.1 & 0.003 \\
\hline Tuberculosis & & & & \\
\hline Yes & $38(60.3)$ & $25(39.7)$ & 10.1 & 0.002 \\
\hline No & $348(78.7)$ & $94(21.3)$ & & \\
\hline ART duration & & & & \\
\hline$<44$ months & $183(70.1)$ & $78(29.9)$ & 8.3 & 0.004 \\
\hline$\geq 44$ months & $203(73.2)$ & $41(16.8)$ & 8.3 & 0.004 \\
\hline Household food securi & & & & \\
\hline Secure & $295(90.2)$ & $32(9.8)$ & 118.5 & 0.0001 \\
\hline insecure & $91(51.1)$ & $87(48.9)$ & 118.3 & 0.0001 \\
\hline Total & $386(76.4)$ & $119(23.6)$ & & \\
\hline
\end{tabular}


TABLE 4: Factors associated with nutritional status of HIV/AIDS patients attending ART in public health facilities, West Shewa Zone, Ethiopia, 2017.

\begin{tabular}{|c|c|c|c|c|}
\hline \multirow{3}{*}{ Variable } & \multicolumn{2}{|c|}{ Undernourished } & \multirow{3}{*}{ COR $(95 \% \mathrm{CI})$} & \multirow{3}{*}{$\operatorname{AOR}(95 \% \mathrm{CI})$} \\
\hline & No & Yes & & \\
\hline & Number (\%) & Number (\%) & & \\
\hline \multicolumn{5}{|l|}{ Sex } \\
\hline Male & $196(81.3)$ & $45(18.7)$ & 1 & 1 \\
\hline Female & $190(72.0)$ & $74(28.0)$ & $1.7(1.1-2.6)^{*}$ & $1.4(0.8-2.3)$ \\
\hline \multicolumn{5}{|l|}{ Marital status } \\
\hline Single & $67(72.8)$ & $25(27.2)$ & $1.4(0.8-2.3)$ & $1.3(0.4-4.3)$ \\
\hline Married & $263(78.1)$ & $74(21.9)$ & 1 & 1 \\
\hline Widowed & $34(66.7)$ & $17(33.3)$ & $1.5(1.1-2.9)^{*}$ & $1.7(0.4-5.7)$ \\
\hline Divorced/separated & $21(88.0)$ & $3(12.0)$ & $0.7(0.2-2.1)$ & $0.5(0.1-4.8)$ \\
\hline \multicolumn{5}{|l|}{ Education } \\
\hline Illiterate & $126(69.6)$ & $55(30.4)$ & $1.6(1.1-2.4)^{*}$ & $1.2(0.7-2.3)$ \\
\hline Literate & $260(80.2)$ & $64(19.8)$ & 1 & 1 \\
\hline \multicolumn{5}{|l|}{ Occupation } \\
\hline Employed & $337(79.2)$ & $86(20.8)$ & 1 & 1 \\
\hline Unemployed & $49(59.8)$ & $33(40.2)$ & $4.1(2.4-7.0)^{* *}$ & $3.4(1.8-5.3)^{* *}$ \\
\hline \multicolumn{5}{|l|}{ WHO clinical stage } \\
\hline Stages I/II & $123(90.4)$ & $13(9.6)$ & 1 & 1 \\
\hline Stages III/IV & $263(70.5)$ & $106(28.8)$ & $3.4(1.9-6.0)^{* *}$ & $3.3(1.8-6.5)^{* *}$ \\
\hline \multicolumn{5}{|l|}{ CD4 count } \\
\hline$<350$ cells $/ \mu \mathrm{l}$ & $281(72.7)$ & $107(27.6)$ & $2.6(1.4-4.9)^{* *}$ & $2.0(1.8-4.2)^{*}$ \\
\hline$\geq 350$ cells $/ \mu \mathrm{l}$ & $105(89.7)$ & $12(10.3)$ & 1 & 1 \\
\hline \multicolumn{5}{|l|}{ Tuberculosis } \\
\hline Yes & $38(60.3)$ & $25(39.7)$ & $2.5(1.4-4.3)^{* *}$ & $2.3(1.3-4.9)^{*}$ \\
\hline No & $348(78.7)$ & $94(21.3)$ & 1 & 1 \\
\hline \multicolumn{5}{|l|}{ ART duration } \\
\hline$<44$ months & $183(70.1)$ & $78(29.9)$ & $2.1(1.4-3.2)^{*}$ & $1.8(1.2-2.9)^{*}$ \\
\hline$\geq 44$ months & $203(73.2)$ & $41(16.8)$ & 1 & 1 \\
\hline \multicolumn{5}{|l|}{ Food security } \\
\hline Secure & $297(90.8)$ & $30(9.2)$ & 1 & 1 \\
\hline Insecure & $84(47.2)$ & $94(52.8)$ & $8.1(5.9-12.8)^{* *}$ & $5.3(2.5-8.3)^{* *}$ \\
\hline
\end{tabular}

Note. Each adjusted odds ratio is adjusted for the remaining variables shown in the table. ART $=$ antiretroviraltherapy; $\mathrm{AOR}=$ adjusted odds ratio; $\mathrm{COR}=$ crude odds ratio. ${ }^{*} P$ value $<0.05 ;{ }^{* *} P$ value $<0.01$.

security status. Unemployed PLWHA were 3.4 more likely to be undernourished compared with employed counterparts, $\mathrm{AOR}=3.4$ (95\% CI: 1.8-5.3). WHO clinical stages III and IV were found to be significant factors associated with under nutrition; PLHIVA in stage III and IV were 3.3 times more likely to be undernourished than WHO stages I and II, AOR $=3.3$ (95\% CI: 1.8-6.5). Similarly, CD4 count was a significant factor associated with undernutrition. PLHIVs with CD4 counts of less than 350 cells/ $\mu$ l were 2 times more likely to be undernourished than their counterparts, $\mathrm{AOR}=2.0$ (95\% CI: 1.8-4.2). Previous OIs with tuberculosis were also found to be the prominent risk factor for undernutrition; TB/HIV coinfected patients had 2.3 significantly higher undernutrition compared to their counterparts, $\mathrm{AOR}=2.3$ (95\% CI: 1.3-4.9). Duration on ART was also significantly associated with nutritional status of HIV/AIDS patients $(\mathrm{AOR}=1.8 ; 95 \% \mathrm{CI}: 1.2-2.9)$. Likewise, household access to food was the strongest factor associated with undernutrition. Household food insecure PLWHA were 5.3 times more likely to be undernourished than household food secured counterparts (AOR $=5.3$; 95\% CI: 2.5-8.3) (Table 4).

\section{Discussion}

This study revealed important information about nutritional status and contextual associated factors among PLWHA who have been on ART in West Shewa Zone, Ethiopia. PLWHA are more vulnerable to malnutrition than the general population and nutritional status is a good predictor of their mortality risk $[5,6]$. The prevalence of undernutrition in this study (23.6\%) was comparable with the findings of other similar studies [7, 15, 16, 19, 20]. Studies conducted in Ethiopia and other developing countries reported high prevalence of undernutrition among PLWHA compared to our finding 
$[12,13,21,22]$. Contrarily, other studies carried out in different study settings revealed lower figures of undernutrition than the result of this study [11, 23-25]. Variation in sociodemographic characteristics of the study participants, in year when studies were conducted, in level of awareness creation made regarding HIV and nutrition, in household food security status, in nutritional support, in opportunistic infections, in severity of the disease, and in adherence to ART treatment might have attributed to divergence in the figures of undernutrition.

This study revealed that unemployed PLWHA were more likely to be undernourished compared with employed counterparts. The higher risk of developing malnutrition in unemployed subjects found in this study is supported by findings of other studies where unemployment promotes poverty, which in turn limits the ability of individual to expend money for food consumption due to low income $[11,15,23,26]$. The implication is improving household income and creating employment opportunities for PLWHAs might be essential component in comprehensive cares for HIV/AIDS patients.

The study showed that WHO clinical stages III and IV have significant effects on the likelihood of malnutrition development among HIV/AIDS patients. Malnutrition is usually encountered at the advanced phase of the HIV infection [27] and anthropometric measurements are lower in symptomatic HIV/AIDS patients classified by WHO stages [28]. This finding was supported by a study conducted in Nepal that reported that WHO clinical stages III and IV were found to be significant risk factors of undernutrition [29]. Similarly, studies done in Ethiopia revealed WHO clinical stage four was significantly associated with malnutrition [11, 12], and study conducted in Uganda revealed that HIV/AIDS patients in WHO stage four usually characterized by severe wasting and food aid to PLWHA delayed HIV disease progress [30]. This finding also supported by a study done in Zimbabwe revealed that patients in advanced stage were more likely to be malnourished [31].

This study also indicated CD4 count was a significant factor associated with undernutrition. PLHIVA with CD4 counts of less than 350 cells/ $\mu$ l were two times more likely to be undernourished than their counterparts. The finding was consistent with study done in Nepal [29]. It also supported by other findings in which patients with CD4 counts less than 200 cells $/ \mu$ l were more likely to be undernourished $[19,20$, 32, 33]. Evidence indicated that the HIV-induced immune impairment and increased subsequent risk of opportunistic infections can worsen nutritional status [34]. Studies also found that malnutrition was associated with lower CD4 count [5], and it tends to decrease CD4 counts recovery and predisposes patients to early death [35]. It was supported by the finding that micronutrient supplements significantly increased CD4 count among PLWHA [36].

Opportunistic infections place PLWHA at a high risk of developing malnutrition [37]. The study showed that tuberculosis (TB) among HIV/AIDS patients was an independent risk factor for undernutrition. This finding was consistent with other similar studies [16, 29, 38-41]. A study done in southern Ethiopia also found number of previous opportunistic infections (OIs) significantly associated with malnutrition [11]. Other studies conducted in Ethiopia also revealed association between malnutrition and tuberculosis $[42,43]$. Evidences also stated that the HIV-induced immune impairment and opportunistic infections can worsen nutritional status [34], and tuberculosis could result in nutritional consequences that commonly precipitate appetite loss, weight loss, and wasting and significantly determine incidence and severity of nutritional status [8].

The study showed that duration of ART treatment was significantly associated with nutritional status of HIV/AIDS patients where significantly lower prevalence of undernutrition was found among patients who were on ART for longer duration. A study conducted in Tanzania also reported that the risk of wasting in HIV patients reduced as ART treatment duration increased [44]. This might be because ART treatment for long period of time improves immunity and reduces risk of opportunistic infections, diarrhea, and vomiting as a result patient could have better appetite, increased dietary intake, and improved nutritional status [44, 45].

Household access to food is a key indicator for predicting undernutrition. Prevalence of household food insecurity was $35.2 \%$. This finding was the lowest compared to other studies in Ethiopia reported from $40.4 \%$ to $87.4 \%[13,14,17,20$, 46-48]. This variation might be as a result of difference in socioeconomical characteristics of the study populations or variation in time when the studies were conducted. The result showed that households with food insecurity were more likely to be undernourished than those PLWHA with adequate access to food. This finding was is in line with other studies [19, 31, 49]. Evidences showed that HIV/AIDS deepens food insecurity and affects the nutritional status of PLWHA leading to weight loss and wasting since PLWHA may no longer hold jobs, manufacture goods, and provide services $[8,50]$ or because of the decrease in productivity $[5,49]$. These findings indicated that the negative interactive effects of undernutrition, inadequate food consumption, and HIV infection demand multisector interventions.

The study had limitations that should be acknowledged. This study was subject to selection bias since the respondents were ones who were actively seeking routine medical care selected from health facilities. They may not represent patients who do not come to the institution from the communities; therefore, generalizability is only for those who are on regular ART follow-up. The cross-sectional nature of the study itself limits conclusions about causeeffect temporal relationships between explanatory variables and undernutrition.

\section{Conclusions}

The findings revealed high prevalence of malnutrition and household food insecurity among people living with HIV/AIDS on antiretroviral therapy in Central Ethiopia. Factors significantly associated with undernutrition among people living with HIV/AIDS were unemployment, WHO clinical stages III/IV, CD4 count less than 350 cells/ $\mu \mathrm{l}$, tuberculosis, duration on ART, and household food insecurity. 
The negative interactive effects of undernutrition, inadequate food consumption, and HIV infection demand effective cross-sectorial integrated programs and effective management of opportunistic infections like tuberculosis.

\section{Abbreviations}

AIDS: Acquired Immune Deficiency Syndrome

AOR: Adjusted odds ratio

ART: Antiretroviral therapy

CI: Confidence interval

IQR: Interquartile range

PLWHA: People living with HIV/AIDS

OIs: Opportunistic infections

TB: Tuberculosis

WHO: World Health Organization.

\section{Conflicts of Interest}

The authors declare that there are no conflicts of interest.

\section{Authors' Contributions}

All investigators proposed, designed, and implemented the study, did the analysis and write-up, and then, read, critically commented, and approved the final manuscript.

\section{Acknowledgments}

The authors would like to thank the study participants for their valuable information and heads of health facilities for their kindly cooperation. This study was financially supported by Ambo University.

\section{References}

[1] World Health Organization(WHO) and UNAIDS UNICEF, Global HIV/AIDS Response: Epidemic Update and Health Sector Progress Towards Universal Access- Progress Report, World Health Organization (WHO), Geneva, Switzerland, 2011.

[2] T. Castleman, E. Seumo-Fosso, and B. Cogill, Food and Nutrition Implications of Antiretroviral Therapy in Resource Limited Settings, Food and Nutrition Technical Assistance Project (FANTA) Academy for Educational Development, Washington, DC, USA, 2003.

[3] Bank W and World Bank and UNAIDS, The Global Economic Crisis and HIV Prevention and Treatment Programmes: Vulnerabilities and Impact, World Bank and UNAIDS, 2009, http://www.unaids.org.

[4] T. Frankenberger, T. Spangler, J. Downen, K. Greenblott, K. Greenaway, and A. Swindale, Food Assistance Program in The Context of HIV, Food and Nutrition Technical Assistance Project(FANTA) and World Food Programme (WFP), Washington, DC, USA, 2007, http://www.fantaproject.org/.

[5] N. A. Benzekri, J. Sambou, B. Diaw et al., "High prevalence of severe food insecurity and malnutrition among HIV-infected adults in Senegal, West Africa," PLoS ONE, vol.10, no. 11, Article ID e0141819, 2015.
[6] M. Suttajit, "Advances in nutrition support for quality of life in HIV/AIDS," Asia Pacific Journal of Clinical Nutrition, vol. 16, no. 1, pp. 318-322, 2007.

[7] D. Molla, M. Fekadu, and B. Dereje, "Nutritional status and associated factors among adult HIV/AIDS clients in Felege Hiwot Referral Hospital, Bahir Dar, Ethiopia," Scientific Journal of Public Health, vol. 1, no. 1, pp. 24-31, 2013.

[8] World Health Organization (WHO), Nutrient Requirements for People Living with HIV/AIDS: Report of a Technical Consultation, 2003.

[9] W. Hu, H. Jiang, W. Chan, S. H. He, B. Deng, W. Y. Wang et al., "Malnutrition in hospitalized people living with HIV/AIDS: evidence from a cross-sectional study from Chengdu, China," Asia Pac Journal of Clinical Nutrition, vol. 20, no. 4, pp. 544550, 2011.

[10] Federal ministory of health (FMOH)., The Federal Democratic Republic of Ethiopia Ministry of Health (FMOH), National Guidelines for HIV/AIDS and Nutrition, Addis Ababa, Ethiopia, 2006.

[11] S. Hailemariam, G. T. Bune, and H. T. Ayele, "Malnutrition: Prevalence and its associated factors in People living with HIV/AIDS, in Dilla University Referral Hospital," Archives of Public Health, vol. 71, no. 1, 2013.

[12] H. Mulu, L. Hamza, and F. Alemseged, "Prevalence of Malnutrition and Associated Factors among Hospitalized Patients with Acquired Immunodeficiency Syndrome in Jimma University Specialized Hospital, Ethiopia," Ethiopian Journal of Health Sciences, vol. 26, no. 3, pp. 217-226, 2016.

[13] T. H. Hadgu, W. Worku, D. Tetemke, and H. Berhe, "Undernutrition among HIV positive women in Humera hospital, Tigray, Ethiopia, 2013: Antiretroviral therapy alone is not enough, cross sectional study," BMC Public Health, vol. 13, no. 1, article no. 943, 2013.

[14] B. Tolasa, B. D. Dereje, T. Temamen, and T. Belachew, "Food Insecurity and Associated Factors among People Living with HIV Attending ART Clinic in Fitche Zonal Hospital , Ethiopia," Journal of Pharmacy and Alternative Medicine, vol. 8, no. 3, pp. 8-17, 2015.

[15] B. Wasie, Y. Kebede, and A. Yibrie, "Nutritional status of adults living with HIV/AIDS at the university of Gonder referral hospital, Northwest Ethioipia," Ethiopian Journal of Health Science, vol. 3, no. 1, pp. 1-12, 2010.

[16] M. Alemayehu, S. Garoma, and H. Fekadu, "Assessment of Adult Nutritional Status and Associated Factors among ART Users in Nekemte Referral Hospital and Health centers," Advanced Life Science Technology, vol. 29, pp. 91-100, 2015.

[17] D. Gedle, G. Mekuria, G. Kumera, T. Eshete, F. Feyera, and T. Ewunetu, "Food Insecurity and its Associated Factors among People Living with HIV/AIDS Receiving Anti-Retroviral Therapy at Butajira Hospital, Southern Ethiopia," Journal of Nutrition \& Food Sciences, vol. 5, no. 2, pp. 2-7, 2015.

[18] J. S. Coates and P. Bilinsky, Household Food Insecurity Access Scale (HFIAS) for Measurement of Food Access: Indicator Guide, Food and Nutrition Technical Assistance Project (FANTA), Academy for Educational Development, Washington, DC, USA, 2007.

[19] L. Amza, T. Demissie, and Halala Y., "Under nutrition and associated factors among adult on highly active antiretroviral therapy in Wolaita Sodo teaching and referral hospital , southern nations nationalities peoples region , Ethiopia," International Journal of Nutrition, vol. 9, pp. 10-19, 2017. 
[20] A. Mitiku, T. A. Ayele, M. Assefa, and A. Tariku, "Undernutrition and associated factors among adults living with Human Immune Deficiency Virus in Dembia District, northwest Ethiopia: An institution based cross-sectional study," Archives of Public Health, vol. 74, no. 1, article no. 33, p. 1, 2016.

[21] R. Zacharia, M. P. Spiemann, A. D. Harries, and F. M. Salanponi, "Moderate to severe malnutrition in a patient with tuberculosis is a risk factor associated with early death," National Tuberculosis Control Program of Malawi Community Health Science Unit Private, p. 65, 2002.

[22] O. Folasire, A. Folasire, and R. Sanusi, "Measures of Nutritional Status and Quality of Life in Adult People Living with HIV/AIDS at a Tertiary Hospital in Nigeria," Journal of Food and Nutrition Sciences, vol. 06, no. 04, pp. 412-420, 2015.

[23] O. A. Uthman, "Prevalence and pattern of HIV-related malnutrition among women in sub-Saharan Africa: A meta-analysis of demographic health surveys," BMC Public Health, vol. 8, article no. 226, 2008.

[24] A. Mangili, D. H. Murman, A. M. Zampini, and C. A. Wanke, "Nutrition and HIV infection: review of weight loss and wasting in the era of highly active antiretroviral therapy from the nutrition for healthy living cohort," Clinical Infectious Diseases, vol. 42, no. 6, pp. 836-842, 2006.

[25] D. G. Feleke, N. Yemanebrhane, and D. Gebretsadik, "Nutritional Status and CD4 Cell Counts in HIV/AIDS Patients under Highly Active Antiretroviral Therapy in Addis Ababa, Ethiopia," Journal of AIDS \& Clinical Research, vol. 08, no. 04, 2017.

[26] P. M. Chege, Z. W. Ndungu, and B. M. Gitonga, "Food security and nutritional status of children under-five in households affected by HIV and AIDS in Kiandutu informal settlement, Kiambu County, Kenya," Journal of Health, Population and Nutrition, vol. 35, no. 1, p. 21, 2016.

[27] N. Deyessa, Y. Berhane, A. Alem, U. Hogberg, and G. Kullgren, "Depression among women in rural Ethiopia as related to socioeconomic factors: a community-based study on women in reproductive age groups," Scandinavian Journal of Public Health, vol. 36, no. 6, pp. 589-597, 2008.

[28] G. Ellen and A. Elizabeth, HIV/AIDS And Nutrition: A Review of Literature And Recommendations for Nutritional Care And Support in Sub-Saharan Africa, 2000.

[29] R. Thapa, A. Amatya, D. P. Pahari, K. Bam, and M. S. Newman, "Nutritional status and its association with quality of life among people living with HIV attending public anti-retroviral therapy sites of Kathmandu Valley, Nepal," AIDS Research and Therapy, vol. 12, no. 1, article no. 14, 2015.

[30] R. Rawat, S. Kadiyala, and P. E. McNamara, "The impact of food assistance on weight gain and disease progression among HIVinfected individuals accessing AIDS care and treatment services in Uganda," BMC Public Health, vol. 10, article no. 316, 2010.

[31] K. C. Takarinda, T. Mutasa-Apollo, B. Madzima et al., "Malnutrition status and associated factors among HIV-positive patients enrolled in ART clinics in Zimbabwe," BMC Nutrition, vol. 3, no. 1, 2017.

[32] K. Fofana, Correlation Between Nutritional Indicators and Low CD4 Count (<200 cells/mm3) among HIV Positive Adults in Kapiri , Zambia 2008-2009 [Thesis], Georgia State University, 2016, http://scholarworks.gsu.edu/iph_theses/432.

[33] A. C. O. D. Santos and A. M. R. Almeida, "Nutritional status and CD4 cell counts in patients with HIV/AIDS receiving antiretroviral therapy," Journal of the Brazilian Society of Tropical Medicine, vol. 46, no. 6, pp. 698-703, 2013.
[34] N. I. Paton, S. Sangeetha, A. Earnest, and R. Bellamy, “The impact of malnutrition on survival and the CD4 count response in HIV-infected patients starting antiretroviral therapy," HIV Medicine, vol. 7, no. 5, pp. 323-330, 2006.

[35] J. D. Kaiser, A. M. Campa, J. P. Ondercin, G. S. Leoung, R. F. Pless, and M. K. Baum, "Micronutrient supplementation increases CD4 count in HIV-infected individuals on highly active antiretroviral therapy: A prospective, double-blinded, placebo-controlled trial," Journal of Acquired Immune Deficiency Syndromes, vol. 42, no. 5, pp. 523-528, 2006.

[36] S. Hussen, T. Belachew, and N. Hussien, "Nutritional status and its effect on treatment outcome among HIV infected clients receiving HAART in Ethiopia: A cohort study," AIDS Research and Therapy, vol. 13, no. 1, article no. 32, 2016.

[37] S. Swaminathan, C. Padmapriyadarsini, B. Sukumar et al., "Nutritional status of persons with HIV infection, persons with HIV infection and tuberculosis, and HIV-negative individuals from southern India," Clinical Infectious Diseases, vol. 46, no. 6, pp. 946-949, 2008.

[38] A. Bhargava, M. Chatterjee, and Y. Jain, "Nutritional status of adult patients with pulmonary tuberculosis in rural central India and its association with Mortality," PLOS ONE, vol. 8, no. 10, Article ID e77979, 2013.

[39] D. C. MacAllan, "Malnutrition in tuberculosis," Diagnostic Microbiology And Infectious Disease, vol. 34, no. 2, pp. 153-157, 1999.

[40] U. E. Schaible and S. H. E. Kaufmann, "Malnutrition and infection: Complex mechanisms and global impacts," PLoS Medicine, vol. 4, no. 5, article e115, 2007.

[41] M. S. Nnyepi, “The risk of developing malnutrition in people living with HIV/AIDS: Observations from six support groups in Botswana," South African Journal of Clinical Nutrition, vol. 22, no. 2, pp. 89-93, 2009.

[42] A. Ahmed, D. Mekonnen, and M. Kindie, "Incidence and Predictors of Tuberculosis among Adult People Living with HIV/AIDS in Afar Public Health Facilities, Northeast Ethiopia," Acquiedr Immuno Deficiency Syndrome, vol. 1, no. 1, pp. 1-8, 2014.

[43] S. Mohammed and T. T. Gebremariam, "Tuberculosis among HIV-positive patients at Butajira Hospital, South-Central Ethiopia," International Journal of Pharmacological Science Research, vol. 6, no. 12, pp. 1406-1411, 2015.

[44] E. Villamor, E. Saathoff, K. Manji, G. Msamanga, D. J. Hunter, and W. W. Fawzi, "Vitamin supplements, socioeconomic status, and morbidity events as predictors of wasting in HIV-infected women from Tanzania," American Journal of Clinical Nutrition, vol. 82, no. 4, pp. 857-865, 2005.

[45] D. Gedle, B. Gelaw, D. Muluye, and M. Mesele, "Prevalence of malnutrition and its associated factors among adult people living with HIV/AIDS receiving anti-retroviral therapy at Butajira Hospital, southern Ethiopia," BMC Nutrition, vol. 1, article 5, pp. 1-11, 2015.

[46] A. Tiyou, T. Belachew, F. Alemseged, and S. Biadgilign, "Food insecurity and associated factors among HIV infected individuals receiving highly active antiretroviral therapy in Jimma zone Southwest," Nutrition Journal, vol. 11, article no. 51, pp. 1-8, 2012.

[47] B. Fekadu, "Determinants of Food Security among Rural Households of Central Ethiopia: An Empirical Analysis, Ethiopia," Ethiopian Journal of Integral Agricalture, vol. 49, no. 4, pp. 299-318, 2010.

[48] M. Asnakew, "Food Insecurity: Prevalence and Associated Factors among Adult Individuals Receiving Highly Active 
Antiretroviral Therapy (HAART) in ART Clinics of Hosanna Town, Hadiya Zone, Southern Ethiopia," Open Access Library Journal of Food, vol. 02, no. 08, pp. 1-9, 2015.

[49] J. Bukusuba, J. K. Kikafunda, and R. G. Whitehead, "Food security status in households of people living with HIV/AIDS (PLWHA) in a Ugandan urban setting," British Journal of Nutrition, vol. 98, no. 1, pp. 211-217, 2007.

[50] L. C. Lvers, K. A. Cullen, K. A. Freedberg, S. Block, J. Coates, and P. Webb, "HIV/AIDS, undernutrition, and food insecurity," Clinical Infectious Diseases, vol. 49, no. 7, pp. 1096-1102, 2009. 


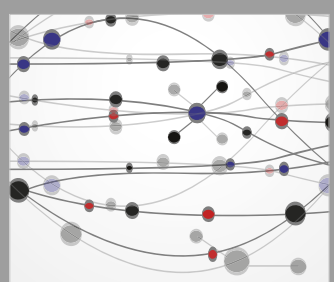

The Scientific World Journal
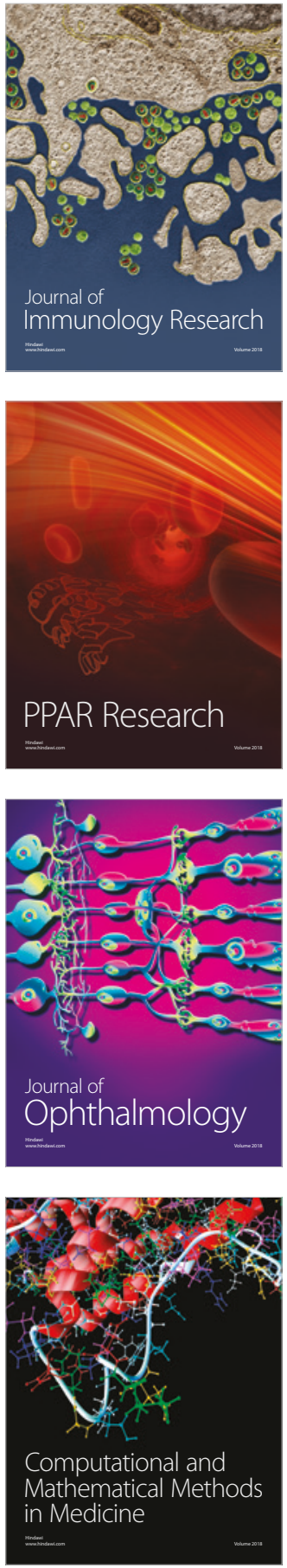

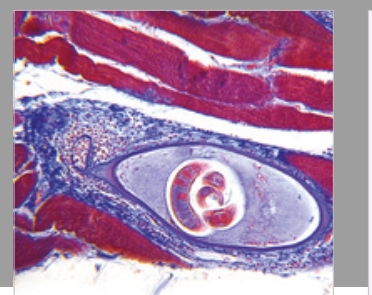

Gastroenterology Research and Practice



\section{Hindawi}

Submit your manuscripts at

www.hindawi.com
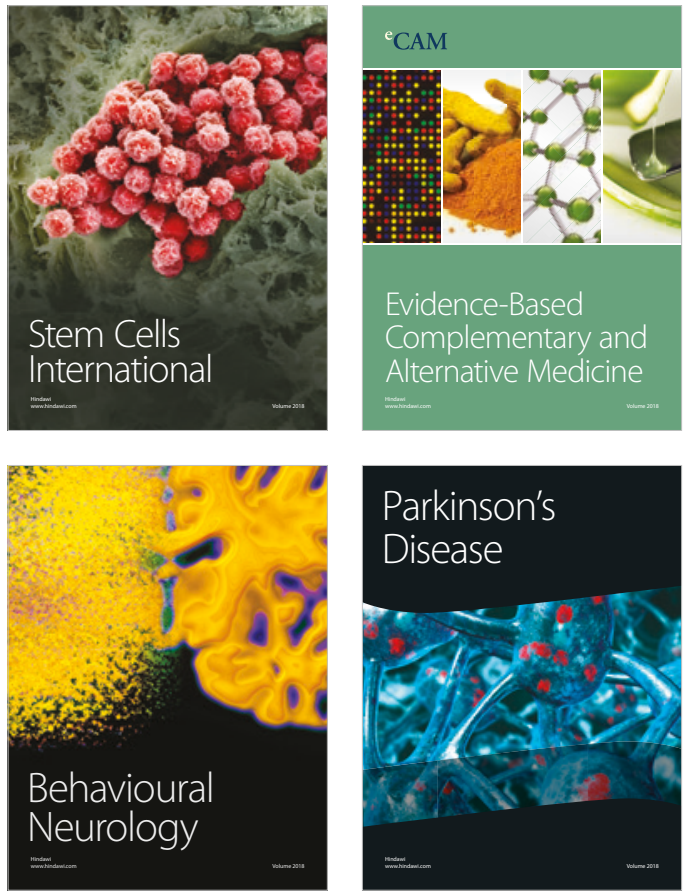

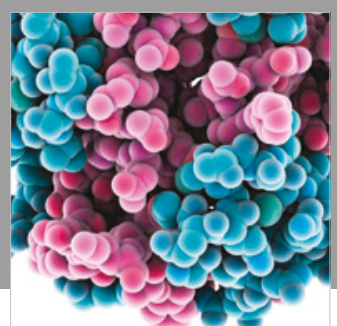

ournal of

Diabetes Research

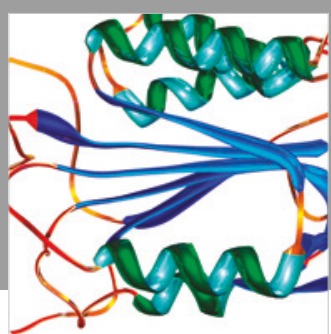

Disease Markers
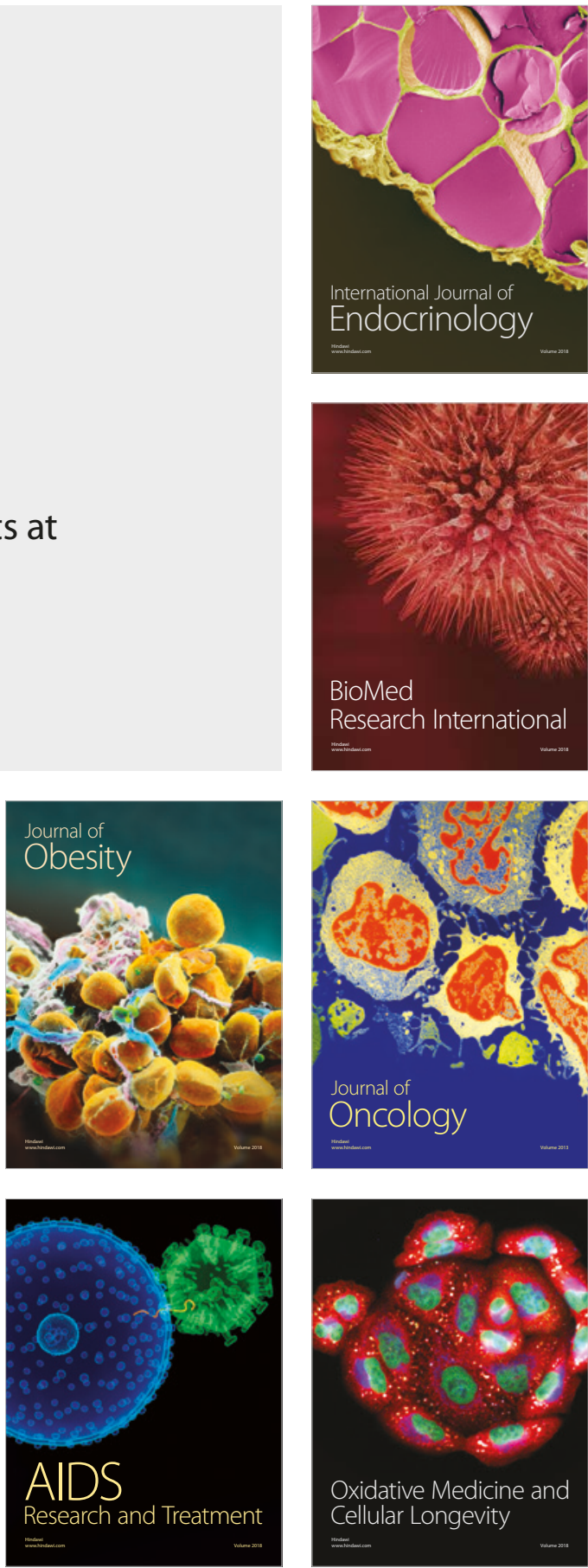